6. Basu D. Requirement of hollow process challenge device for monitoring hollow and complex instruments sterilization: a simulator for proper sterility assurance. Infection Control Hosp Epidemiol 2019;40:951-952.

7. Collier R. The ethics of reusing single-use devices. CMAJ 2011;183:1245.

8. Lee RC, Berzins S, Alfieri N. Single-use device reuse risks. Can J Infect Control 2007;22:142-146.
9. Fast O, Fast C, Fast D, Veltjens S, Salami Z, White MC. Limited sterile processing capabilities for safe surgery in low-income and middle-income countries: experience in the Republic of Congo, Madagascar, and Benin. BMJ Glob Health 2017;2 suppl 4:e000428.

\title{
An influenza A outbreak in Iranian individuals following Arba'een foot pilgrimage from October to December 2019
}

\author{
Rasoul Mirzaei $\mathrm{PhD}^{1}$ and Milad $\mathrm{Abdi}^{2,3}$ \\ ${ }^{1}$ Department of Microbiology, School of Medicine, Hamadan University of Medical Sciences, Hamadan, Iran, ${ }^{2}$ Student Research Committee, Faculty of Medicine, \\ Iran University of Medical Sciences, Tehran, Iran and ${ }^{3}$ Department of Microbiology, School of Medicine, Iran University of Medical Sciences, Tehran, Iran
}

To the Editor-Influenza A (flu) is a viral infection that involves the human respiratory system mostly in cold seasons. ${ }^{1-3}$ For most individuals, this infection is not problematic, but it can cause death. ${ }^{1}$ The transmission of this disease is done in 2 direct and indirect ways. ${ }^{4}$ Direct transmission occurs person-to-person: respiratory droplets are transmitted from infected to healthy individuals over a short distance. ${ }^{4}$ The influenza virus can survive for hours in cold conditions and in low humidity in the environment. Hand contact with contaminated surfaces or objects can transmit the virus indirectly thorough inoculation of the eyes, nose, and mouth. ${ }^{4}$ Individuals at high risk for developing deadly flu are members of the following groups ${ }^{5}$ : (1) adults $>65$ years of age, (2) children $<5$ years of age, (3) pregnant women, (4) individuals with weakened immune defenses, (5) individuals with chronic disorders (eg, heart disease, asthma, kidney disease, diabetes as well as liver disorder), and (6) obese individuals. Up to 650,000 deaths annually are associated with respiratory diseases from seasonal influenza, according to new estimates by the Centers for Disease Control and Prevention (CDC), the World Health Organization, and their global health partners. ${ }^{6}$ In 2019, in Western Asia, influenza activity remained elevated overall and continued to increase in Iraq, Israel, Jordan, Turkey, and Yemen. ${ }^{7}$

During the 20th and 21st centuries, 5 influenza pandemics have been recorded: Spanish (1918-1920), Asian (1957-1958), Hong Kong (1968-1969), Russian (1977-1978), and H1N1/09 pandemic flu (2009-2010). ${ }^{8}$ During the last pandemic of influenza (JuneNovember 2009), 2,662 cases of pandemic influenza A (H1N1) were detected in Iran. Among these cases, 58 patients died. ${ }^{8}$ The most common influenza A outbreaks in Iran had been $\mathrm{H} 1 \mathrm{~N} 1$, the most severe form of the disease, which accounted for $\sim 90 \%$ of all cases. ${ }^{9}$ Seasonal influenza is among the most prevalent infectious diseases in travelers. ${ }^{10}$ In tropical areas, influenza viruses may circulate throughout the year with several seasonal peaks, whereas in the moderate climate zones, circulation is largely limited to 1 or 2 peaks in the fall and winter months. ${ }^{10}$ Studies have shown the relationship between overcrowding and increased prevalence of influenza. ${ }^{11}$ Thus, whenever and wherever high population density

Author for correspondence: Rasoul Mirzaei, E-mail: rasul.micro92@gmail.com Cite this article: Mirzaei R and Abdi M. (2020). An influenza A outbreak in Iranian individuals following Arba'een foot pilgrimage from October to December 2019. Infection Control \& Hospital Epidemiology, 41: 627-628, https://doi.org/10.1017/ ice. 2020.49 occurs, the likelihood of transmission and spread of influenza is higher. Globally, one of the most overcrowded events is Arba'een, and it is accompanied by a high incidence of the flu every year.

Arba'een, the 40th day, is a religious event observed in many Islamic countries; it is one of the largest pilgrimage gatherings on Earth. ${ }^{12}$ In this event, up to 17 million people from Islamic countries such as Iran, Pakistan, Turkey, Afghanistan, Azerbaijan, Lebanon, Kuwait, Bahrain, Saudi Arabia travel to Karbala city in Iraq. ${ }^{12} \mathrm{~A}$ significant percentage of this population is Iranian. ${ }^{12}$ In 2018, 123,000 Iranian pilgrims had symptoms of illness upon returning to the border, and $\sim 5,000$ needed treatment due to flu. ${ }^{13}$ In 2019, 30,000 cases of influenza were reported overall, and 106 of these patients died. According to reports from Ministry of Health and Medical Education of Iran, between the beginning of October 2019 and December 2019, after pilgrims returned from Iraq, 8,333 people went to medical centers because of respiratory illness, half of whom required $>2$ days of hospitalization due to the severity of respiratory illness and 106 of whom died. ${ }^{14}$ The rest were discharged with outpatient or temporary hospitalization. ${ }^{14}$ Many factors are involved in influenza prevalence in the Arba'een. ${ }^{3}$ (1) Many pilgrims suffer from general weakness and fatigue due to a lengthy walk; some walk $\sim 200$ $\mathrm{km}$. (2) Overcrowding occurs in huge tents called mukeb, which cover thousands of people, and congestion in and around the shrine is high, increasing the risk of flu 10 -fold. ${ }^{11}$ (3) Hygiene is poor due to inadequate availability of showers and toilets. (4) The Arba'een event takes place during the cold-weather season in a geographic location with moderate climate. (5) Access to appropriate food during travel is limited. When a person has the flu, it is crucial to eat small amounts of the right foods to provide it with energy and nutrients for recovery). (6) Inadequate sleep can affect the immune system. Pilgrims who do not get quality sleep or enough sleep are more likely to get sick after being exposed to the flu virus. (7) Individuals from different countries can carry mutant and virulent influenza virus. Because of these problems and conditions in the Arba'een pilgrimage, recommend several ways for pilgrims to prevent flu outbreaks in these places ${ }^{15}$ :

1) Wash hands several times a day with liquid soap and water as well as alcohol rub if it is available.

2) Avoid contact with contaminated hands, eyes, and mouth. 
3) Use respiratory masks during close contact with people, and try to change the masks often.

4) Maintain several meters distance from other pilgrims.

5) Avoid contact with other pilgrims who appear ill.

6) Obtain vaccination (high-risk individuals).

7) Avoid shaking hands and kissing during greetings.

8) Wear mask and gloves during the pilgrimage and touching the shrine.

Also, if individuals appear with signs and symptoms of flu, the following measures should be taken ${ }^{15}$ :

1) Use a mask to cover the mouth and nose.

2) Cover the nose and mouth with their arm/sleeve or a napkin when sneezing or coughing.

3) Placed used napkin or tissue in a plastic bag, then close the bag and throw it in the trash.

Observing such measures can greatly reduce the spread of influenza virus during the Arba'een pilgrimage.

Acknowledgments. This work was supported by the Hamadan University of Medical Sciences.

Financial support. No financial support was provided relevant to this article.

Conflicts of interest. All authors report no conflicts of interest relevant to this article.

\section{References}

1. Pavia A. One hundred years after the 1918 pandemic: new concepts for preparing for influenza pandemics. Curr Opin Infect Dis 2019;32: 365-371.

2. Lee BE, Mukhi SN, Drews SJ. Association between patient age and influenza A subtype during influenza outbreaks. Infect Control Hosp Epidemiol 2010;31:535-537.
3. Álvarez F, Froes F, Rojas AG, Moreno-Perez D, Martinón-Torres F. The challenges of influenza for public health. Future Microbiol 2019;14: 1429-1436.

4. Zhang N, Li Y. Transmission of influenza A in a student office based on realistic person-to-person contact and surface touch behaviour. Int $J$ Environ Res Public Health 2018;15:1699.

5. Chow EJ, Doyle JD, Uyeki TM. Influenza virus-related critical illness: prevention, diagnosis, treatment. Crit Care 2019;23:214-214.

6. Up to 650,000 people die of respiratory diseases linked to seasonal flu each year. World Health Organization website. https://www.who.int/en/newsroom/detail/14-12-2017-up-to-650-000-people-die-of-respiratory-diseaseslinked-to-seasonal-flu-each-year. Published December 14, 2017. Accessed February 18, 2020.

7. Influenza update 359. World Health Organization website. https://www. who.int/influenza/surveillance_monitoring/updates/latest_update_GIP_ surveillance/en/. Published January 22, 2020. Accessed February 18, 2020.

8. Hatami H. History of influenza: pandemics in Iran and the world. Int I Infect 2016;3:e36672.

9. Moghoofei M, Monavari SH, Mostafaei S, et al. Prevalence of influenza A infection in the Middle East: a systematic review and meta-analysis. Clin Respir J 2018;12:1787-1801.

10. Goeijenbier M, van Genderen P, Ward B, Wilder-Smith A, Steffen R, Osterhaus A. Travellers and influenza: risks and prevention. $J$ Travel Med 2016;24:taw078.

11. Aligne CA. Overcrowding and mortality during the influenza pandemic of 1918. Am J Public Health 2016;106:642-644.

12. Shia pilgrims flock to Karbala for Arba'een climax. BBC News website. https:// www.bbc.com/news/world-middle-east-30462820. Published December 14, 2014. Accessed February 18, 2020.

13. Solmaz, N. Possible outbreak of flu after return of Iranian pilgrims from Iraq. The Independent Persian website. https://www.independentpersian. com/node/25811. Published October 22, 2019. Accessed February 18, 2020.

14. Ministry of Health: Influenza casualties reach 9. Islamic Reppublic News Agency. https://www.irna.ir/news/83603379/. Published January 1, 2019. Accessed February 18, 2020.

15. Healthy habits to help prevent flu. Centers for Disease Control and Prevention website. https://www.cdc.gov/flu/prevent/actions-prevent-flu.htm. Published November 7, 2019. Accessed February 18, 2020.

\title{
Applying behavioral frameworks to antimicrobial stewardship
}

\author{
Nisha Thampi MD, MSc ${ }^{1}$ (1), Julia E. Szymczak $\mathrm{PhD}^{2,3}$ and Jerome A. Leis MSc, MD ${ }^{4,5}$ \\ ${ }^{1}$ Department of Pediatrics, Children's Hospital of Eastern Ontario, University of Ottawa, Ottawa, Ontario, Canada, ${ }^{2}$ Department of Biostatistics, Epidemiology and \\ Informatics, Perelman School of Medicine, University of Pennsylvania, Philadelphia, Pennsylvania, United States, ${ }^{3}$ Division of Infectious Diseases, Children's \\ Hospital of the University of Pennsylvania, Philadelphia, Pennsylvania, United States, ${ }^{4}$ Department of Medicine, Sunnybrook Health Sciences Centre, Toronto, \\ Ontario, Canada and ${ }^{5}$ Department of Medicine and Centre for Quality Improvement and Patient Safety and University of Toronto, Toronto, Ontario, Canada
}

To the Editor-The effectiveness of healthcare improvement initiatives is highly dependent on the social, psychological, organizational and cultural dynamics of clinical settings. ${ }^{1,2}$ Historically, in antimicrobial stewardship, most interventions have been broadly implemented without taking these important contextual factors into account, despite research demonstrating the importance of adaptation to the local context. ${ }^{3,4}$ Furthermore, the recommended metrics for assessing the impact of interventions do not take into consideration the dynamics between the clinician and

Author for correspondence: Nisha Thampi, Email: nthampi@cheo.on.ca

Cite this article: Thampi N, Szymczak JE, and Leis JA. (2020). Applying behavioral frameworks to antimicrobial stewardship. Infection Control \& Hospital Epidemiology, 41: 628-630, https://doi.org/10.1017/ice.2020.40 antimicrobial stewardship team, making it more difficult to predict the long-term success of a program. ${ }^{5}$ Existing behavior-change models can be applied to determine how the intended recipient of an intervention might respond to initiatives that seek to change behavior in order to optimize the uptake and sustainability of antimicrobial stewardship interventions.

Prochaska and DiClemente's transtheoretical model (TTM) is one such framework. It consists of 5 stages that conceptualize how people change their health behavior. ${ }^{6}$ In the initial stage, precontemplation, the individual does not intend to take action within the next 6 months. In stage 2 , contemplation, action is intended within the next 6 months. Stage 3 is preparation, in which action is intended within the next 30 days; stage 4 is action, in which 